\title{
The quantitative genetic basis of female and male body size and their implications on the evolution of body size dimorphism in the house cricket Acheta domesticus (Gryllidae)
}

\author{
Raúl Cueva del Castillo \\ University of Toronto at Mississauga, Biology Department, Mississanga, Canada.
}

\begin{abstract}
Few theoretical and experimental studies have analyzed the genetic basis of body size dimorphism. Since the evolutionary response to selection depends of the genetic variance in a population it is to be expected that traits under selection would have smaller genetic variance than traits not affected by selection. The evolution of sexual size dimorphism is affected by the genetic correlation between females and males, with the most dimorphic traits showing smaller genetic correlations between the sexes. As result of the differences in the intensity of sexual selection between the sexes, it is expected that the levels of genetic variance would be larger in females than males. I analyzed the genetic additive variance underlying six traits of Acheta domesticus, and the genetic correlations between females and males. The most dimorphic trait with the smallest genetic correlation between the sexes was forewing length, this trait showing genetic variance only in females. It may be that sexual selection acting on male traits has depleted the genetic variance not only in male traits but also for those female traits that have a large genetic correlation with male traits. It is also possible that the evolution of sexual dimorphism in $A$. domesticus could be constrained as a result of the large genetic correlation between the sexes.
\end{abstract}

Key words: Acheta domesticus, body size, dimorphism, heritability, sexual selection.

Received: March 11, 2004; Accepted: March 31, 2005.

\section{Introduction}

Phenotypic differences between sexes can arise as result of sexual differences in the intensity or mode of selection (Badyaev et al., 2000; Krausaar and Blanckernhorn, 2002). Falconer (1989) has pointed out that the evolutionary response to selection depends on the quantitative genetic variance in the population and that the amount of genetic variance present in a population can reflect the historical consequences of natural selection, because of which it is to be expected that genetic variance would be depleted by natural selection.

Since sexual selection is generally stronger on males than females (Andersson, 1994), it is to be expected that the levels of genetic variance underlying sexually-selected traits would be larger in females than males because of the differences in the intensity of sexual selection between the sexes. However, the genetic variance of traits undergoing natural selection can be affected by several genetic factors, including the relationship of each trait to fitness (Falconer

Present address: Universidad Nacional Autónoma de México, FES Iztacala, Laboratorio de Ecología, Apartado Postal 314, 54090 Edo. de México, México. E-mail: rcueva@miranda.ecologia. unam.mx.
1989), genetic correlation between characters (Stearns, 1992; Roff, 1996; Houle, 2001) and the effect of the environment on the traits, including whether the traits are condition-dependent (Rowe and Houle, 1996; Schlichting and Pigliucci, 1998; Nager et al., 2000, Tomkins et al., 2004).

When calculating the effects of traits that show sexual dimorphism it is necessary to consider genetic correlations between sexes (Lande, 1980). If the correlation between the sexes is large there are two alternative scenarios; the genetic variance in females can decrease in a correlated response to selection pressure on males, or, if natural selection is operating in a different way on females than on males, it is possible that the genetic variance will be maintained in the population due to an equilibrium between female and male selective pressures (Simmons and Ward, 1991). Despite these evolutionary implications, only a few experimental studies have analyzed the genetic basis of body size dimorphism (Simmons and Ward, 1991; Reeve and Fairbairn, 1996; Merila et al., 1998; Badyaev and Hill, 2000).

The study presented in this paper analyzes the genetic variance of six traits of female and male Acheta domesticus (house crickets). Female house crickets prefer the song patterns of large males, which, consequently, have higher mating success (Gray, 1997). As a consequence of this sexual 
selection I hypothesized that non-dimorphic traits should show less genetic variance than dimorphic traits (Rowe and Houle, 1996), for which males are expected to show less genetic variance than females. Differences between the genetic variance of dimorphic traits should be related to the genetic correlation between sexes, with female traits that are more closely correlated with male traits exhibiting less genetic variance than traits with lower genetic correlations.

\section{Material and Methods}

\section{Cricket stocks}

A half-sib cross-breeding design was performed to estimate the heritability of six morphological traits of the house cricket Acheta domesticus (Gryllidae), from a four year old laboratory stock held at the university of Toronto. This stock having originally been derived from about 200 house crickets obtained from a local pet supply store. In this experiment each male was crossed with two females by placing a male and a female together in a $500 \mathrm{ml}$ plastic container for three days, after which the first female was replaced with another which was also left with the male for three days. After exposure to the male, the females were transferred to individual containers with vermiculite until their eggs hatched, the offspring being transferred to one-litre housing jars until they reached sexual maturity. In all cases food (cricket chow; Fluker Farms) and water were provided ad libitum each third day. When the offspring were close to sexual maturity the rearing jars were checked daily for newly molted adults, which were removed from the jars, sacrificed and individually preserved in $70 \%(\mathrm{w} / \mathrm{v})$ aqueous ethanol. At the end of the experiment, digital pictures of the experimental progenies were taken with a video camera (Hitachi; VK-C370) and an image analyzer (Windias 1.5 Delta-T Devices Ltd.) used to measure the following parameters for each sex: pronotum length and width, left and right hind tibia length, and left and right forewing length.

\section{Statistical analysis}

\section{Body size dimorphism}

Multivariate analysis of variance (MANOVA) was performed to test for body size dimorphism of the six fe- male and male morphological traits, $t$-tests being conducted to detect which of the six measured traits were sexually dimorphic. The coefficient of variation $(\mathrm{CV})$ were also estimated for each trait.

\section{Genetic correlation}

The family mean values of each sex were estimated for the dimorphic traits, and Pearson correlations performed between sexes for each trait. Because the family mean method may be biased when family size is small $(\approx<20)$ the confidence intervals for the correlations were estimated using a jackknife procedure (Roff and Preziosi, 1994). Monte Carlo simulations were used to obtain the confidence intervals of the significant correlation coefficients.

\section{Heritability}

For traits showing sexual dimorphism, heritability was calculated for each sex. In non-dimorphic traits the heritability obtained was a combined female+male heritability estimation. For each trait nested ANOVAs (Model II, Type III SS, Sokal and Rohlf, 1995) using the GLM module of the JMP procedure (SAS, 1995) were performed to determine the presence of a significant sire effect. Genetic variance components which differed from zero were tested using the SAS Proc Mixed module (SAS, 1999), this analysis showing whether or not a given additive genetic variance estimate is different from zero. Heritability was estimated as the ratio of the sire component of variance to the total phenotypic variance.

\section{Results}

\section{Sexual size dimorphism}

The analysis indicated that morphological differences existed between the sexes (MANOVA Wilks's $\lambda=0.922$; $\left.\mathrm{F}_{(6 ; 257)}=3.566 ; \mathrm{p}<0.001\right)$. Left and right hind tibia length, left and right forewing length, and pronotum width all showed sexual dimorphism. These traits were larger in females than males, while thorax length did not differ between sexes (Table 1). Moreover, females showed more variation than males as regards forewings and the pronotum (Table 2).

Table 1 - Mean plus standard error (SE) of the six morphological traits in female and male of Acheta domesticus crickets. The $P$ values are from two-tailed $t$ test (262 degrees of freedom) of differences between sexes.

\begin{tabular}{lcccc}
\hline Trait $(\mathrm{mm})$ & Females & Males & $t$ & $\mathrm{p}$ \\
\hline Left hind tibia length & $9.086(0.063)$ & $8.757(0.059)$ & 3.794 & $<0.0001$ \\
Right hind tibia length & $9.097(0.059)$ & $8.852(0.064)$ & 2.794 & 0.0005 \\
Left forewing length & $10.346(0.083)$ & $10.062(0.077)$ & 2.510 & 0.013 \\
Right forewing length & $10.363(0.083)$ & $10.095(0.077)$ & 2.361 & 0.019 \\
Pronotum length & $2.941(0.033)$ & $2.940(0.031)$ & 0.011 & 0.990 \\
Pronotum width & $4.219(0.038)$ & $4.103(0.038)$ & 2.193 & 0.029 \\
\hline
\end{tabular}


Table 2 - Coefficients of variation (CV) of the six morphological traits measured in female and male Acheta domesticus crickets.

\begin{tabular}{|c|c|c|c|c|c|c|}
\hline \multirow[t]{2}{*}{ Sex } & \multicolumn{2}{|c|}{ Hind tibia } & \multicolumn{2}{|c|}{ Forewing } & \multirow[t]{2}{*}{ Pronotum } & \multirow[t]{2}{*}{ Pronotum } \\
\hline & Left & Right & Left & Right & & \\
\hline Females & 11.46 & 10.22 & 8.71 & 8.50 & 9.69 & 9.65 \\
\hline Males & 13.72 & 10.80 & 7.68 & 7.84 & 8.41 & 8.41 \\
\hline
\end{tabular}

\section{Genetic correlations}

High genetic correlations were found between all the measured traits (Table 3a-c). Genetic correlations between the sexes were significant and varied from 0.888 between the female left hind tibia length and the male right hind tibia length to 0.661 between male pronotum width and female right forewing. The lowest genetic correlations were found between female and male forewing length and all traits of the opposite sex (Table 3c). The genetic correlations remain significant after Monte Carlo simulations.

\section{Heritability}

Female traits showed significant levels of sire variation (Table 4a). However, only their forewing lengths showed significant heritability. Left and right female hind tibia length were marginally non-significant $\left(h^{2}=0.427\right.$; $\mathrm{p}=0.064 ; h^{2}=0.398 ; \mathrm{p}=0.061$; respectively), as were the maternal effects (Dam Sire) on female left, and male left and right tibias (Table 5).

\section{Discussion}

The results showed that tibia length, forewing length and pronotum width are sexually dimorphic in $A$. domesticus. Females were larger than males in all three measures, and there were differences between sexes in the genetic correlations. The smaller correlations were found between female forewing lengths with all the male traits (Table 3c). Interestingly, in four of the six traits females

Table 3a - Genetic correlations between the six morphological traits of Acheta domesticus females $(\mathrm{n}=123)$. Jackknife significance levels are shown between parenthesis.

\begin{tabular}{|c|c|c|c|c|c|}
\hline & Right hind tibia length & Left forewing length & Right forewing length & Pronotum width & Pronotum length \\
\hline Left hind tibia length & $0.995(<0.001)$ & $0.914(<0.001)$ & $0.900(<0.001)$ & $0.954(<0.001)$ & $0.728(<0.017)$ \\
\hline Right hind tibia length & & $0.904(<0.001)$ & $0.900(<0.001)$ & $0.954(<0.001)$ & $0.757(0.011)$ \\
\hline Left forewing length & & & $0.996(0.001)$ & $0.933(<0.001)$ & $0.670(0.033)$ \\
\hline Right forewing length & & & & $0.933(<0.001)$ & $0.696(0.025)$ \\
\hline Pronotum width & & & & & $0.803(0.005)$ \\
\hline
\end{tabular}

Table 3b - Genetic correlations between the six morphological traits of Acheta domesticus males $(\mathrm{n}=141)$. Jackknife significance levels are shown between parenthesis.

\begin{tabular}{|c|c|c|c|c|c|}
\hline & Right hind tibia length & Left forewing length & Right forewing length & Pronotum width & Pronotum length \\
\hline Left hind tibia length & $0.955(<0.001)$ & $0.722(0.018)$ & $0.728(0.016)$ & $0.883(<0.001)$ & $0.923(<0.001)$ \\
\hline Right hind tibia length & & $0.781(0.007)$ & $0.770(0.009)$ & $0.955(<0.001)$ & $0.924(<0.001)$ \\
\hline Left forewing length & & & $0.781(0.007)$ & $0.796(0.006)$ & $0.706(0.022)$ \\
\hline Right forewing length & & & & $0.783(0.007)$ & $0.687(0.028)$ \\
\hline Pronotum width & & & & & $0.888(<0.001)$ \\
\hline
\end{tabular}

Table 3c - Genetic correlations between female and male $(\mathrm{n}=264)$ dimorphic traits of Acheta domesticus. Jackknife significance levels are shown between parentheses.

\begin{tabular}{|c|c|c|c|c|c|}
\hline \multirow[b]{2}{*}{ Female Trait } & \multicolumn{5}{|c|}{ Male trait } \\
\hline & Left hind tibia length & Right hind tibia length & Left forewing length & Right forewing length & Pronotum width \\
\hline Pronotum width & $0.865(<0.001)$ & $0.881(<0.001)$ & $0.843(0.006)$ & $0.848(0.005)$ & $0.810(0.001)$ \\
\hline Left hind tibia length & $0.856(<0.001)$ & $0.888(<0.001)$ & $0.746(0.003)$ & $0.730(0.004)$ & $0.780(<0.001)$ \\
\hline Right hind tibia length & $0.867(0.001)$ & $0.887(0.001)$ & $0.730(0.002)$ & $0.719(0.002)$ & $0.788(<0.001)$ \\
\hline Left forewing length & $0.704(<0.001)$ & $0.725(<0.001)$ & $0.788(<0.001)$ & $0.792(<0.001)$ & $0.696(<0.001)$ \\
\hline Right forewing length & $0.710(0.002)$ & $0.742(0.002)$ & $0.797(<0.001)$ & $0.799(<0.001)$ & $0.661(<0.001)$ \\
\hline
\end{tabular}


Table 4a - ANOVA of five dimorphic traits of Acheta domesticus. Sire and dams nested in sire (Dam [Sire]) were considered random effects.

\begin{tabular}{|c|c|c|c|c|c|c|c|c|c|c|}
\hline \multicolumn{11}{|c|}{ Left hind tibia length } \\
\hline \multirow[b]{2}{*}{ Source } & \multirow[b]{2}{*}{ SS } & \multicolumn{3}{|c|}{ Females } & \multirow[b]{2}{*}{$r^{2}$} & \multirow[b]{2}{*}{ SS } & \multicolumn{3}{|c|}{ Males } & \multirow[b]{2}{*}{$r^{2}$} \\
\hline & & df & F & $\mathrm{p}$ & & & $\mathrm{df}$ & $F$ & $\mathrm{p}$ & \\
\hline Sire & 27.222 & 9 & 3.406 & 0.033 & 0.427 & 18.056 & 9 & 1.764 & 0.192 & 0.274 \\
\hline Dam [Sire] & 9.125 & 10 & 3.400 & $<0.001$ & 0.143 & 11.8755 & 10 & 4.327 & $<0.001$ & 0.180 \\
\hline Error & 27.638 & 121 & & & & 33.202 & 121 & & & \\
\hline
\end{tabular}

Right hind tibia length

\begin{tabular}{|c|c|c|c|c|c|c|c|c|c|c|}
\hline \multirow[b]{2}{*}{ Source } & \multirow[b]{2}{*}{ SS } & \multicolumn{3}{|c|}{ Females } & \multirow[b]{2}{*}{$r^{2}$} & \multirow[b]{2}{*}{ SS } & \multicolumn{3}{|c|}{ Males } & \multirow[b]{2}{*}{$r^{2}$} \\
\hline & & df & $F$ & $\mathrm{p}$ & & & $\mathrm{df}$ & $F$ & $\mathrm{p}$ & \\
\hline Sire & 25.150 & 9 & 3.464 & 0.031 & 0.370 & 18.484 & 9 & 2.182 & 0.117 & 0.288 \\
\hline Dam [Sire] & 8.250 & 10 & 2.422 & 0.012 & 0.121 & 9.806 & 10 & 3.718 & $<0.001$ & 0.153 \\
\hline Error & 67.832 & 121 & & & & 64.077 & 121 & & & \\
\hline
\end{tabular}

Left forewing length

\begin{tabular}{|c|c|c|c|c|c|c|c|c|c|c|}
\hline \multirow[b]{2}{*}{ Source } & \multirow[b]{2}{*}{ SS } & \multicolumn{3}{|c|}{ Females } & \multirow[b]{2}{*}{$r^{2}$} & \multirow[b]{2}{*}{ SS } & \multicolumn{3}{|c|}{ Males } & \multirow[b]{2}{*}{$r^{2}$} \\
\hline & & $\mathrm{df}$ & $F$ & $\mathrm{p}$ & & & $\mathrm{df}$ & $F$ & $\mathrm{p}$ & \\
\hline Sire & 39.682 & 9 & 3.737 & 0.024 & 0.326 & 35.819 & 9 & 2.629 & 0.071 & 0.358 \\
\hline Dam [Sire] & 12.038 & 10 & 2.126 & 0.028 & 0.099 & 15.778 & 10 & 3.740 & 0.001 & 0.158 \\
\hline Error & 58.324 & 121 & & & & 51.040 & 121 & & & \\
\hline
\end{tabular}

Right forewing length

\begin{tabular}{|c|c|c|c|c|c|c|c|c|c|c|}
\hline \multirow[b]{2}{*}{ Source } & \multirow[b]{2}{*}{ SS } & \multicolumn{3}{|c|}{ Females } & \multirow[b]{2}{*}{$r^{2}$} & \multirow[b]{2}{*}{ SS } & \multicolumn{3}{|c|}{ Males } & \multirow[b]{2}{*}{$r^{2}$} \\
\hline & & df & $F$ & $\mathrm{p}$ & & & $\mathrm{df}$ & $F$ & $\mathrm{p}$ & \\
\hline Sire & 36.374 & 9 & 3.421 & 0.032 & 0.301 & 32.299 & 9 & 2.542 & 0.078 & 0.315 \\
\hline Dam [Sire] & 12.052 & 10 & 2.089 & 0.031 & 0.099 & 14.666 & 10 & 3.105 & 0.001 & 0.143 \\
\hline Error & 59.424 & 121 & & & & 57.144 & 121 & & & \\
\hline
\end{tabular}

Pronotum width

\begin{tabular}{|c|c|c|c|c|c|c|c|c|c|c|}
\hline \multirow[b]{2}{*}{ Source } & \multirow[b]{2}{*}{ SS } & \multicolumn{3}{|c|}{ Females } & \multirow[b]{2}{*}{$r^{2}$} & \multirow[b]{2}{*}{ SS } & \multicolumn{3}{|c|}{ Males } & \multirow[b]{2}{*}{$r^{2}$} \\
\hline & & df & $F$ & $\mathrm{p}$ & & & $\mathrm{df}$ & $F$ & $\mathrm{p}$ & \\
\hline Sire & 4.864 & 9 & 2.341 & 0.098 & 0.234 & 6.146 & 9 & 2.012 & 0.141 & 0.005 \\
\hline Dam [Sire] & 2.356 & 10 & 2.160 & 0.026 & 0.113 & 3.518 & 10 & 2.773 & 0.004 & 0.229 \\
\hline Error & 20.734 & 121 & & & & 15.350 & 121 & & & \\
\hline
\end{tabular}

Key: SS = Sum of Square; $d f=$ degrees of freedom; $F=$ F-value; $\mathrm{p}=$ probability level; $r^{2}=$ explained variance.

Table 4b - ANOVA of a not dimorphic trait; pronotum length of Acheta domesticus. Sire and Dam nested in Sire (Dam [Sire]) was considered random effect.

\begin{tabular}{lrrrrr}
\hline Source & \multicolumn{1}{c}{ SS } & df & $F$ & p & $r^{2}$ \\
\hline Sire & 6.787 & 9 & 2.667 & 0.055 & 0.190 \\
Dam [Sire] & 3.489 & 11 & 3.026 & 0.0008 & 0.097 \\
Error & 25.475 & 263 & & & \\
\hline
\end{tabular}

Key: SS = Sum of Square; $d f=$ degrees of freedom; $F=$ F-value; $\mathrm{p}=$ probability level; $r^{2}=$ explained variance.

showed more variation than males (Table 2). Nevertheless, only female forewing length showed significant heritability. These results are consistent with my predictions. In general, sexual selection is stronger on males than females
(Andersson, 1994). As a result of female choice, the genetic variance in male traits that are preferred by females and female traits strongly genetically correlated with them (see Tables $4 \mathrm{~b}$ and $5 \mathrm{~b}$ ), could have been eroded by sexual selec- 
Table 5a - Variance components estimates and heritabilities $\left(h^{2}\right)$ of five dimorphic traits of Acheta domesticus $\left(\mathrm{n}_{\text {females }}=123 ; \mathrm{n}_{\text {males }}=141\right)$. Sire and Dams nested in Sire were considered random effects. $P$-values were obtained from a $Z$-test (variance component divided by standard error (SE)).

\begin{tabular}{|c|c|c|c|c|c|c|c|c|c|c|}
\hline \multirow[b]{3}{*}{ Source } & \multicolumn{10}{|c|}{ Left hind tibia length } \\
\hline & \multicolumn{3}{|c|}{ Females } & \multirow[b]{2}{*}{$h^{2}$} & \multirow[b]{2}{*}{$\mathrm{p}$} & \multicolumn{3}{|c|}{ Males } & \multirow[b]{2}{*}{$h^{2}$} & \multirow[b]{2}{*}{$\mathrm{p}$} \\
\hline & Estimate & SE & Z & & & Estimate & $\mathrm{SE}$ & Z & & \\
\hline Sire & 0.340 & 0.224 & 1.52 & 0.427 & 0.064 & 0.151 & 0.130 & 1.16 & 0.270 & 0.123 \\
\hline Dam [Sire] & 0.166 & 0.105 & 1.35 & & 0.057 & 0.141 & 0.094 & 1.52 & & 0.063 \\
\hline \multirow[t]{3}{*}{ Residual } & 0.291 & 0.040 & 7.16 & & $<0.001$ & 0.266 & 0.034 & 7.72 & & $<0.001$ \\
\hline & \multicolumn{10}{|c|}{ Right hind tibia length } \\
\hline & \multicolumn{3}{|c|}{ Females } & \multirow[b]{2}{*}{$h^{2}$} & & \multicolumn{3}{|c|}{ Males } & & \\
\hline Source & Estimate & SE & Z & & $\mathrm{p}$ & Estimate & $\mathrm{SE}$ & $\mathrm{Z}$ & $h^{2}$ & $\mathrm{p}$ \\
\hline Sire & 0.318 & 0.206 & 1.54 & 0.398 & 0.061 & 0.155 & 0.134 & 1.16 & 0.275 & 0.123 \\
\hline Dam [Sire] & 0.116 & 0.086 & 1.35 & & 0.088 & 0.141 & 0.093 & 1.52 & & 0.063 \\
\hline \multirow[t]{3}{*}{ Residual } & 0.364 & 0.051 & 7.16 & & $<0.001$ & 0.266 & 0.035 & 7.72 & & $<0.001$ \\
\hline & \multicolumn{8}{|c|}{ Left forewing length } & & \\
\hline & \multicolumn{3}{|c|}{ Females } & & & \multicolumn{3}{|c|}{ Males } & & \\
\hline Source & Estimate & SE & Z & $h^{2}$ & $\mathrm{p}$ & Estimate & $\mathrm{SE}$ & Z & $h^{2}$ & $\mathrm{p}$ \\
\hline Sire & 0.469 & 0.283 & 1.66 & 0.412 & 0.048 & 0.087 & 0.123 & 0.71 & 0.154 & 0.239 \\
\hline Dam [Sire] & 0.089 & 0.076 & 1.18 & & 0.119 & 0.199 & 0.123 & 1.61 & & 0.053 \\
\hline \multirow[t]{3}{*}{ Residual } & 0.579 & 0.079 & 7.32 & & $<0.001$ & 0.278 & 0.036 & 7.70 & & $<0.001$ \\
\hline & \multicolumn{8}{|c|}{ Right forewing length } & & \\
\hline & \multicolumn{3}{|c|}{ Females } & & & \multicolumn{3}{|c|}{ Males } & & \\
\hline Source & Estimate & SE & Z & $h^{2}$ & $\mathrm{p}$ & Estimate & SE & Z & $h^{2}$ & $\mathrm{p}$ \\
\hline Sire & 0.432 & 0.262 & 1.64 & 0.388 & 0.050 & 0.200 & 0.162 & 1.24 & 0.241 & 0.107 \\
\hline Dam [Sire] & 0.086 & 0.076 & 1.12 & & 0.132 & 0.151 & 0.114 & 1.32 & & 0.093 \\
\hline \multirow[t]{3}{*}{ Residual } & 0.593 & 0.081 & 7.33 & & $<0.001$ & 0.478 & 0.062 & 7.71 & & $<0.001$ \\
\hline & \multicolumn{8}{|c|}{ Pronotum width } & & \\
\hline & \multicolumn{3}{|c|}{ Females } & & & \multicolumn{3}{|c|}{ Males } & & \\
\hline Source & Estimate & SE & Z & $h^{2}$ & $\mathrm{p}$ & Estimate & SE & Z & $h^{2}$ & $\mathrm{p}$ \\
\hline Sire & 0.062 & 0.046 & 1.32 & 0.296 & 0.093 & 0.061 & 0.053 & 1.15 & 0.260 & 0.124 \\
\hline Dam [Sire] & 0.034 & 0.024 & 1.46 & & 0.081 & 0.046 & 0.035 & 1.33 & & 0.092 \\
\hline Residual & 0.113 & 0.015 & 7.24 & & $<0.001$ & 0.127 & 0.016 & 7.72 & & $<0.001$ \\
\hline
\end{tabular}

tion. The smallest genetic correlation between female forewing length and male characters can explain why the forewing was the most dimorphic trait and showed significant genetic variance levels. When the genetic correlations between the sexes are small the independent evolution of male and females is possible and sexual dimorphism can evolve (Lande, 1980; Lynch and Walsh, 1998).

If the genetic variance in male traits under sexual selection is small the possibility that an evolutionary response to selection occurs would be reduced and environmental factors like diet, or temperature can strongly affect the phenotypes (Moreteau et al., 1994; Nager et al., 2000; Thompson, 1999). In this study body size traits variation appear not to be reliable indicators of male genetic quality but can suggest the condition of the male to a potential mate. Nevertheless, Bakker and Pomiankowski (1995) found high genetic variance in male traits under sexual selection. Rowe and Houle (1996) consider that sexually selected traits maintain genetic variation because they are influenced by a large number of loci, which results in a relatively high frequency of mutations in genes coding for their phenotypic expression. However, other alternative hypotheses are possible. If genetic correlation between the sexes is high, and natural and/or sexual selection are operating in different ways on each sex, the genetic variance would be maintained in the population as result of a tradeoff (Simmons and Ward, 1991). Also, if the genetic correlation between the sexes is small, and females traits are not the 
Table 5b - Mixed variance model for heritability $\left(h^{2}\right)$ of a non-dimorphic trait (pronotum length) of Acheta domesticus $(\mathrm{n}=264)$. Sire and Dam nested in Sire (Dam Sire) was considered random effect.

\begin{tabular}{lccccc}
\hline Source & Estimate & SE & Z & $h^{2}$ & $p$ \\
\hline Sire & 0.028 & 0.023 & 1.26 & 0.183 & 0.103 \\
Dam [Sire] & 0.020 & 0.014 & 1.44 & 0.075 \\
Residual & 0.105 & 0.009 & 10.99 & $<0.001$ \\
\hline
\end{tabular}

Key: $\mathrm{SE}=$ Standard Error; $Z=Z$-value $\mathrm{p}=$ probability level.

target of selection, some level of genetic variance could be restored to next generation males as result of sexual recombination.

Sexually selected traits are homologous characters, so the analysis of inter-sexual genetic variance and genetic correlations between sexes can assist understanding the evolution of sexual dimorphism and the effects of sexual and natural selection in the levels of genetic variance within sexes.

\section{Acknowledgements}

I am indebted to Juan Fornoni, Darryl Gwynne and Juan Nuñez-Farfán for their helpful discussion and critical comments on this manuscript. Valuable suggestions on the manuscript were made by the associated editor of the journal and two anonymous reviewers. Cynthia Thomas and Sonia Malhotra provided indispensable laboratory assistance with rearing the crickets. This work was supported by a Natural Sciences and Engineering Research Council of Canada grant to DTG. Raúl Cueva del Castillo was supported by a CONACyT posdoctoral scholarship in the University of Toronto at Mississauga.

\section{References}

Andersson M (1994) Sexual Selection. Princeton Univ Press, New Jersey, 599 pp.

Badyaev AV and Hill GE (2000) The evolution of sexual dimorphism in the house finch. I. Population divergence in morphological covariance structure. Evolution 54:1784-1794.

Badyaev AV, Hill GE, Stoehr AM, Nolan PM and McGraw KJM (2000) The evolution of sexual size dimorphism in the house finch II. Population divergence in relation to local selection. Evolution 54:2134-2144.

Bakker TCM and Pomiankowski A (1995) The genetic basis of female mate preferences. J Evol Biol 8:129-171.

Falconer DS (1989) Introduction to quantitative genetics. Longman, Harlow, 438 pp.

Gray DA (1997) Female house crickets, Acheta domesticus, prefer the chirps of large males. Anim Behav 54:1553-1562.

Houle D (2001) The character problem in life history evolution. In: Wagner, GP (ed) The Character Concept in Evolutionary Biology. Academic Press, San Diego, pp 109-140.

Krausaar U and Blanckernhorn WU (2002) Population variation in sexual selection and its effects on size and allometry in two dung fly species with contrasting sexual size dimorphism. Evolution 56:307-321.
Lande R (1980) Sexual dimorphism, sexual selection, and adaptation in polygenic characters. Evolution 34:292-305.

Lynch M and Walsh B (1998) Genetics and Analysis of Quantitative Traits. Sinauer Sunderland, Massachusetts, 980 pp.

Merila J, Sheldon BC and Ellegren H (1998) Quantitative genetics of sexual size dimorphism in the collared flycatcher, $\mathrm{Fi}$ cedula albicollis. Evolution 52:870-876.

Moreteau DJR, Gauthier JP, Petavy G, Stockel A and Imasheva AG (1994) Reaction norms of size characters in relation to growth temperature in Drosophila melanogaster. An isofemale lines analysis. Genet Sel Evol 26:229-251.

Nager RG, Keller LF and van Noordwijk AJ (2000) Understanding natural selection on traits that are influenced by environmental conditions. In: Mousseau TA, Sinervo B and Endler J (eds) Adaptive Genetic Variation in the Wild. Oxford Univ. Press, Oxford, pp 95-113.

Reeve JP and Fairbairn D (1996) Sexual size dimorphism as a correlated response to selection on body size: An empirical test of the quantitative genetic model. Evolution 50:1927-1938.

Roff DA (1996) The evolution of genetic correlations: An analysis of patterns. Evolution 50:1392-1403.

Roff DA and Preziosi R (1994) The estimation of the genetic correlation: The use of the jackknife. Heredity 73:544-548.

Rowe L. and Houle D (1996) The lek paradox, condition dependence and genetic variance in sexually selected traits. P Roy Soc London B 263:1415-1421.

SAS (1995) JMP ${ }^{\circledR}$. Statistics and Graphics Guide, Version 3.1. SAS Institute Inc., Cary, North Carolina.

SAS (1999) SAS PROC MIXED. Version 8.2. SAS Institute, Cary, North Carolina.

Schlichting CD and Pigliucci M (1998) Phenotypic evolution: A reaction norm perspective. Sinauer Sunderland, Massachusetts, $387 \mathrm{pp}$.

Simmons LW and Ward PI (1991) The heritability of sexually dimorphic traits in the yellow dung fly Scathophaga stercoraria (L.). J Evol Biol 4:593-601.

Sokal, RR and Rohlf FJ (1995) Biometry. Freeman, New York, $887 \mathrm{pp}$.

Stearns S (1992) The evolution of Life Histories. Oxford University Press. Oxford.

Thompson DB (1999) Genotype-environment interaction and the ontogeny of diet-induced phenotypic plasticity in size and shape of Melanoplus femurrubrum (Orthoptera, Acrididae). J Evol Biol 12:38-48.

Tomkins JL, Radwan J, Kotiaho JS and Tregenza T (2004) Genetic capture and resolving the lek paradox. Trends Ecol Evol 19:323-328.

Associate Editor: Louis Bernard Klaczko 